\title{
Research on the Integration Development of Shiyan's Cultural Industry and Tourism Industry Under the Background of Industrial Convergence*
}

\author{
Sanwei Liu \\ College of Economics and Management \\ Hubei Automotive Industrial Institute \\ Shiyan, 442002
}

\author{
Na Zheng** \\ College of Economics and Management \\ Hubei Automotive Industrial Institute \\ Shiyan, 442002 \\ **Corresponding Author
}

\author{
Lei Guo \\ College of Economics and Management \\ Hubei Automotive Industrial Institute \\ Shiyan, 442002
}

\begin{abstract}
The trend of mutual integration and interactive development between the cultural industry and the tourism industry in Shiyan City has become increasingly prominent. The mutual promotion between the two has attracted more and more attention from the Shiyan municipal government, enterprises and scholars. Based on the combing and summarizing of the literature, this paper analyzes the development status of the cultural industry and tourism industry in Shiyan City and the integration status of the two, and finds out the main problems in the integration process of the two major industries in Shiyan City and provides targeted measures to promote the integration and development of the cultural industry and tourism industry in Shiyan City.
\end{abstract}

Keywords-tourism industry; cultural industry; industrial integration; Shiyan City

\section{INTRODUCTION}

Culture is the soul of tourism, and tourism is an important manifestation of culture. In the context of globalization, culture and tourism have grown into two of the most promising emerging industries in the development of modern economy and society, and the two major industries of culture and tourism have become increasingly integrated and developed, thus leading to the new industrial structure - the integration development of culture and tourism. Located in the middle and upper reaches of the Han River, Shiyan City is rich in natural resources and profound in cultural heritage. It has unique advantages in the integration of the two industries. During the "Thirteenth Five-Year Plan" period, the government promoted tourism as the second pillar industry of the city, and used the tourism industry as an engine to drive the tourism of the tertiary industry and even the comprehensive development of the region, forming a new pattern of global tourism for the

*Project: Hubei University of Automotive Industry College Student Innovation Fund Project (Project No.: DC2018074). interconnection of scenic spots, eating and lodging, travel and entertainment with landscape city interaction, ecology and human integration as well as resorts and scenic areas combination. Therefore, studying the integration and development of Shiyan City's cultural industry and tourism industry has great practical significance for Shiyan City to build an international tourism destination and to create a strategic goal of global tourism.

\section{THE DEVELOPMENT STATUS QUO OF TOURISM INDUSTRY AND CULTURAL INDUSTRY IN SHIYAN CITY}

\section{A. Development Status Quo of Tourism Industry in Shiyan City}

In recent years, with the strong support of the Shiyan Municipal Party Committee and the Municipal Government, the city's tourism industry has seized the opportunity of great cultural development and prosperity, and has achieved fruitful development results. The income of the tourism industry in Shiyan City is growing steadily, and its contribution to the economy is becoming more and more prominent 
TABLE I. TOURISTS AND INCOME STATISTICS FOR SHIY AN CITY FROM 2007 TO 2016

\begin{tabular}{llllll}
\hline Year & $\begin{array}{c}\text { Total Number of } \\
\text { Tourists (10,000 } \\
\text { Person-Time) }\end{array}$ & $\begin{array}{c}\text { Total Number of } \\
\text { Overseas Tourists } \\
(\mathbf{1 0 , 0 0 0} \text { Person-Time) }\end{array}$ & $\begin{array}{c}\text { Total Tourism } \\
\text { Revenue } \\
\text { (100 Million Yuan) }\end{array}$ & $\begin{array}{c}\text { Number of } \\
\text { Tourists } \\
\text { Growth Rate (\%) }\end{array}$ & $\begin{array}{c}\text { Total Tourism } \\
\text { Revenue Growth } \\
\text { Rate (\%) }\end{array}$ \\
\hline 2007 & 760 & 6.1 & 31.6 & 14 & 12.8 \\
\hline 2008 & 921 & 7.6 & 41.8 & 21.18 & 32.2 \\
\hline 2009 & 1123.7 & 9.1 & 62.32 & 22.01 & 41.8 \\
\hline 2010 & 1477.11 & 10.94 & 89.3 & 30.38 & 38.64 \\
\hline 2011 & 1864.1 & 13.23 & 119.28 & 26.2 & 33.57 \\
\hline 2012 & 2333.33 & 16.8 & 161.19 & 25.17 & 35.14 \\
\hline 2013 & 2910.94 & 17.3 & 202.19 & 24.75 & 25.44 \\
\hline 2015 & 3435.4 & 17.78 & 242.73 & 18.02 & 20.05 \\
\hline 2016 & 4010 & 18.27 & 299.8 & 16.72 & 23.51 \\
\hline & 18.8 & 361.22 & 17.22 & 20.47 \\
\hline
\end{tabular}

It can be seen from "Table I" above that all aspects of the tourism industry in Shiyan City have developed well. The total number of tourists and the total tourism revenue has shown a steady growth trend. In 2015, the tourism reception volume exceeded 40 million passengers and the total tourism revenue was nearly 30 billion yuan, in the 10 years from 2007 to 2016, the total tourism revenue of Shiyan City increased year by year, the average growth rate of total tourism revenue was $28.36 \%$, and the tourism industry developed well.

TABLE II. Proportion of Tourism OutPut VAlue In Shiyan City From 2007 to 2016

\begin{tabular}{|c|c|c|c|c|}
\hline Year & $\begin{array}{l}\text { Tourism Output Value } \\
\text { (100 Million Yuan) }\end{array}$ & Output Value & $\begin{array}{l}\text { arious Industries (100 } \\
\text { n Yuan) }\end{array}$ & $\begin{array}{c}\text { The Proportion of Tourism } \\
\text { Industry }\end{array}$ \\
\hline \multirow{2}{*}{2007} & \multirow{2}{*}{31.6} & Tertiary Industry & 167.83 & $18.83 \%$ \\
\hline & & gross product & 411.42 & $7.68 \%$ \\
\hline \multirow{2}{*}{2008} & \multirow{2}{*}{41.8} & Tertiary Industry & 204.92 & $20.40 \%$ \\
\hline & & gross product & 487.64 & $8.57 \%$ \\
\hline \multirow{2}{*}{2009} & \multirow{2}{*}{62.32} & Tertiary Industry & 229.69 & $27.13 \%$ \\
\hline & & gross product & 550.96 & $11.31 \%$ \\
\hline \multirow{2}{*}{2010} & \multirow{2}{*}{89.3} & Tertiary Industry & 256.88 & $34.76 \%$ \\
\hline & & gross product & 736.78 & $12.12 \%$ \\
\hline \multirow{2}{*}{2011} & \multirow{2}{*}{119.28} & Tertiary Industry & 302.46 & $39.44 \%$ \\
\hline & & gross product & 851.25 & $14.01 \%$ \\
\hline \multirow{2}{*}{2012} & \multirow{2}{*}{161.19} & Tertiary Industry & 344.27 & $46.82 \%$ \\
\hline & & gross product & 955.68 & $16.87 \%$ \\
\hline \multirow{2}{*}{2013} & \multirow{2}{*}{202.19} & Tertiary Industry & 390.55 & $51.77 \%$ \\
\hline & & gross product & 1080.59 & $18.71 \%$ \\
\hline \multirow{2}{*}{2014} & \multirow{2}{*}{242.73} & Tertiary Industry & 439.50 & $55.23 \%$ \\
\hline & & gross product & 1200.82 & $20.21 \%$ \\
\hline \multirow{2}{*}{2015} & \multirow{2}{*}{299.8} & Tertiary Industry & 506.53 & $59.19 \%$ \\
\hline & & gross product & 1300.12 & $23.06 \%$ \\
\hline \multirow{2}{*}{2016} & \multirow{2}{*}{361.22} & Tertiary Industry & 574.16 & $62.91 \%$ \\
\hline & & gross product & 1429.15 & $25.28 \%$ \\
\hline
\end{tabular}

According to the analysis in "Table II", the proportion of tourism industry output value of Shiyan City in the tertiary industry has increased year by year. Since 2013, the proportion of tourism industry in the tertiary industry has reached $51.77 \%$, more than half, especially in 2016, it has reached $62.91 \%$. It shows that the tourism industry plays an important role in the tertiary industry. In addition, the proportion of the tourism industry's output value in Shiyan City also showed a continuous upward trend. Until 2016, the tourism industry's output value has reached $25.28 \%$ of Shiyan's GDP, and the Shiyan City's tourism industry is developing steadily. The proportion of the output value of tourism industry in Shiyan City to the output value of the tertiary industry and the total output value has increased year by year. It can be found that the tourism industry, as the second pillar industry of Shiyan City, plays an important role in the economic development of Shiyan City.

\section{B. Development Status Quo of Cultural Industry in Shiyan City}

In 2017, the cultural industry above designated size in Shiyan City achieved an operating income of 2.41 billion yuan, a year-on-year increase of $14.6 \%$, and an increase of 2.9 percentage points over the province. From the perspective of sub-sectors, the cultural manufacturing industry completed operating income of 973 million yuan, a year-on-year increase of $16.8 \%$, accounting for $40.3 \%$ of total revenue, and cultural wholesale and retail industry units completed operating income of 886 million yuan, an increase of $9.8 \%$ over the previous year. The proportion of total income was 36.7\%. There are 4,466 employees in the cultural industry in the city. Among them, the cultural service industry employs up to 2,118 people, accounting for $47.4 \%$; the cultural manufacturing industry employs 1,723 people, accounting for $38.6 \%$; and the 
cultural wholesale and retail industry employs 625 people, accounting for only $14 \%$.

In recent years, under the guidance and support of the Shiyan municipal government, the cultural industry in Shiyan
City has begun to develop. The development of the cultural industry relies on rich cultural resources. The profound cultural resources of Shiyan City have created favorable conditions for the development of the cultural industry.

TABLE III. MAIN CUltural Institutions In SHiyan City, 2007-2016

\begin{tabular}{|c|c|c|c|c|c|c|c|c|c|c|}
\hline Cultural Institution & 2007 & 2008 & 2009 & 2010 & 2011 & 2012 & 2013 & 2014 & 2015 & 2016 \\
\hline Artistic performance group (one) & 8 & 8 & 8 & 8 & 8 & 8 & 8 & 7 & 7 & 7 \\
\hline Cultural Center (one) & 10 & 10 & 9 & 9 & 10 & 10 & 10 & 10 & 10 & 10 \\
\hline Public library(one) & 8 & 8 & 8 & 8 & 8 & 8 & 8 & 8 & 8 & 8 \\
\hline Museum (one) & 4 & 4 & 6 & 8 & 11 & 12 & 12 & 12 & 12 & 12 \\
\hline
\end{tabular}

It can be seen from "Table I" "Table III" that the number of cultural institutions in Shiyan City is small, and the development of cultural resources in Shiyan City is not deep enough. Therefore, the development of cultural industries is still in its infancy. The number of artistic performance groups is even decreasing, indicating that the development of the performing arts in Shiyan City is in its infancy. The number of cultural centers and public libraries has remained basically unchanged for 10 years, and the number of museums has increased from 2007 to 2012. It shows that the construction of cultural institutions in Shiyan City has developed but the trend is not obvious.

In addition, in 2016, the Shiyan City Government issued a series of policies such as the "13th Five-Year Plan for the Culture and Sports Press and Publication Radio and Film Industry Development in Shiyan City" and pointed out the direction for the development of the cultural industry in Shiyan City. In recent years, Shiyan City has promoted the inheritance and revitalization of opera culture, strengthened the creation of literary and artistic works, carried out a series of mass cultural activities, strengthened the construction of public cultural service system, and strengthened supervision over the cultural market. These measures have promoted the cultural industry to be developed actively.

\section{The Current Situation of the Integration of Cultural Industry and Tourism Industry in Shiyan City}

The cultural industry and tourism industry in Shiyan City showed the following points in the process of integration and development:

1) The development of the human landscape has achieved initial results: Shiyan City firmly grasped the construction of "Fangling Cultural Circle". In 2006, the Times Literature and Art Publishing House published the "Fangling emperor exile record" and held the first publishing ceremony in Fang County. The Wujiagou folktale was approved by the State Council to be included in the first batch of national intangible cultural heritage. On December 7, 2013, the original ecological poem "Shanfeng" of Fang County was broadcast live on CCTV 3, and achieved great results. Fang County is investing in the newly-built Chinese Poetry Culture Park.

2) The effect of tourism culture brand construction is obvious: Tourism culture brands such as "Wu Dang Culture", "Yin Jifu·Shijing Culture", "Qi Xi Culture" and "Nvwa Culture" were initially successfully created, "Wudang
Culture", "Tianhe Qixi Folk Customs" in Yunxi, and "Yin Jifu·Shijing Source" in Fang County, Danjiang "Canglang Water" and Zhuxi "Taoyuan Gallery" have been commended by the province. The construction of the "one county, one product" tourism culture brand has promoted the infrastructure construction in all parts of Shiyan City, launched the popular tourism culture products, promoted the development of the tourism industry, and promoted the rapid development of regional economic, social and cultural development.

3) Cultural performance and tourism combined: On January 12, 2016, City Federation of Literary and Art Circles, City Writers Association, City Art School, and Shiyan Radio and Television Station jointly held the Shiyan City 2016 New Year Poetry. On January 17th, the first plum blossom tourism festival of Hubei Canglang Mountain was held jointly by Shiyan City Federation of Literary and Art Circles, City Poetry Society, Canglang Mountain National Forest Park and City Musicians Association, and a large-scale poetry concert was held, creating a business card for forest culture tourism in northwest Hubei.

In general, the cultural industry of Shiyan City and the tourism industry have achieved mixed achievements, but the integration is not deep, and the integration characteristics are not clear enough.

\section{PROBLEMS IN THE INTEGRATION AND DEVELOPMENT} OF CULTURAL INDUSTRY AND TOURISM INDUSTRY IN SHIYAN CITY

\section{A. The Development of Cultural Resources Is Generally Commercialized and Too Much Emphasis on Economic Interests}

Although the economy is a carrier of traditional culture, cultural resources can undoubtedly be commercialized, and the promotion of commercialization is more conducive to the popularization of culture, but in some areas of Shiyan City, when developing cultural resources, economic benefits are often placed first instead of paying attention to the protection of cultural resources, making the development of cultural resources pan-commercial, and even abusing the individual elements of traditional culture, making the traditional culture degraded. The blind development of cultural resources, the commercialization of traditional culture, and the distortion of traditional culture destroyed the originality and particularity of 
traditional culture. For example, the ancient buildings in Huanglong Town have experienced hundreds of years of wind and rain erosion, but they are still relatively intact. However, in the operation of modern commercialization, many merchants have built up modern buildings in the Huanglong Ancient Town Protection Zone in pursuit of economic interests, which destructed the relatively rare ancient town buildings.

\section{B. The Sense of Integration Development Is Not Strong and There Is No Long-term Planning}

At present, Shiyan City does not have a long-term plan for the development of cultural industries and tourism industry, and the integration of the two is not included in the scope of economic performance assessment. In addition, cultural enterprises do not have scale at present and the grades are relatively low, so the number of tourism cultural products is small, and there is a lack of quality products. The integration of tourism industry and cultural industry has not formed a broad social consensus and lacks a social environment for integrated development.

\section{Insufficient Publicity}

In recent years, the Shiyan municipal government and enterprises have paid more and more attention to the promotion of media promotion and reporting on tourism development. However, there are some problems in the promotion of tourism resources in Shiyan City. The main performances are as follows: first, point to area, the content is not rich enough; second, the theme element is single, lacks the big tourism concept; third, the report is relatively dull. Although the cultural tourism resources of Shiyan City are rich and varied, there are few people who know it because of the insufficient publicity.

\section{The Cultural Level of Cultural Resources Is Low}

There is currently no cultural resource in Shiyan City to form industrialized operation. The key to the development of the cultural industry is to have a large number of cultural enterprises with market competitiveness. Most of the cultural units in Shiyan City are administrative institutions, and they do not have the dominant position in the market. The government management agencies only work hard on the government's investment, career establishment, and management power of the public institutions and the development of the cultural industry is placed in a secondary position. In addition, cultural products are single, there is no serialized and regularized cultural consumption mode and consumer groups, resulting in a single form of consumption, without large fixed consumption sites, consumption areas and consumer products, which is an important reason for the low degree of industrialization.

\section{E. Lack of Specialized Management Agencies}

After the development of the cultural industry and the tourism industry to a certain extent, the two major industries will achieve better integration and development. However, the current business entities of the cultural industry are scattered in various industries and involve multiple departments. In this case, the cultural industry development has been in a spontaneous, independent, mutually restrictive, small-scale development and operation, which seriously hinders the integration of cultural industries and tourism industry. In addition, the core radio, television, the Internet, and various news media of the cultural industry are also independent and incompetent, and are in vicious competition, the government's management of cultural enterprises is only to collect fees, but also to maintain social stability and to ensure political propaganda, rarely think, guide, and support from an industrial perspective. The Shiyan City Cultural and Sports New and Contemporary Bureau establishes an institution with culture, sports, and news broadcasting, instead of setting up several separate institutions, so we can know that Shiyan City lacks a special management organization.

\section{F. The Government and Enterprises Have Little Cooperation}

The government's financial input is basically business cultural units and mainly managed personnel funds. There is basically no investment in the infrastructure of the cultural industry and industrial development. The functional departments are not aware of the service of cultural industries and cultural enterprises. The access transparency of cultural industry projects is not high. However, the existing cultural enterprises are small in scale, scattered, and low in specialization. There are no influential cultural products in the existing cultural enterprises, and there is no cultural enterprise that has influence and competitiveness in the whole province and the whole country. The cooperation between the government and enterprises is not strong enough, making the animation creative industry, one of the core layers of the existing cultural industry, still in a blank state.

\section{G. The Industry Chain Is Short, and the Integration Benefits Are Not Obvious}

The closer the cultural industry and the tourism industry are, the stronger their relevance and the more obvious the benefits of integration. However, in the initial stage of integration, the connections between enterprises are often less, and the integration ability between resources is often weak, so the industrial chain of the tourism industry and the cultural industry is extended shortly. Taking cultural infrastructure as an example, the tourism function has not been taken into account in the allocation of cultural facilities, resulting in insufficient tourist attraction.

\section{H. The Talent Structure Is Unreasonable and the Loss Is Serious}

At present, the business ability and academic level of the employees in the tourism industry in Shiyan City are relatively low, and the talents with high academic qualifications and high professional titles are relatively scarce, and the talent structure is unreasonable. On the other hand, tourism enterprises have a greater demand for front-line service staff, but college students are generally reluctant to engage in front-line service, which makes it difficult for enterprises to recruit talents. Moreover, most tourism enterprises are small in scale and cannot provide compensation and promotion space comparable to those in coastal areas. The employment discrimination of the service industry in the whole society leads to the lack of professional pride of employees, so local talents will also be outflowing, 
and it is even less likely to attract and introduce out-of-town talents.

\section{Low Comprehensive Development of Tourism Resources}

At present, the tourism culture products are mainly based on sightseeing scenery, lacking cultural entertainment activities, and there are fewer programs of cultural performances, and the participation of tourists is also poor, and there is no local characteristic, so the tourism products lack of competitiveness in the market. Taking the well-developed Wudang Mountain at present as an example, it is the leading product of Shiyan City, but Wudang Mountain's Taoist cultural tourism resources have not been fully developed, there is a relatively large gap between Wudang Mountain and the scenic spots of the same type it terms of comprehensive development level, scale, impact and benefits. The tourism activities of Wudang Mountain are basically based on viewing and the content is monotonous. Second, the development of tourism products in Shiyan City is not enough. There is a lack of special tourism products in various scenic spots, and tourism products lack new ideas, which affect the desire of tourists to purchase.

\section{COUNTERMEASURES FOR THE INTEGRATION AND DEVELOPMENT OF CULTURAL INDUSTRY AND TOURISM INDUSTRY IN SHIYAN CITY}

\section{A. Developing Appropriate Development Plans and Increasing Tourism Promotion}

The diversification of demand is an important reason for promoting tourism industry and cultural industry. Through government's active guidance to tourism consumers, the consumers' consumption is not limited to the visit to natural landscapes and cultural landscapes, but is more inclined to the diversified product demand combining culture, technology and characteristics, thus promoting the integration of tourism industry and cultural industry.

The Shiyan municipal government should, according to the development of tourism industry and cultural industry, give full play to the advantages of resources, formulate appropriate development plans, ensure the coordination of tourism and cultural industry development, and maximize the integration of tourism and cultural resources. On the one hand, they must rationally develop and utilize tourism cultural resources, and develop in multiple directions. On the other hand, they must highlight the characteristics of Shiyan City, give full play to the advantages of Taoist culture and automobile city culture, and integrate resources naturally to enhance the taste of Shiyan City's tourism culture. In addition, the cultural industry and the tourism industry should achieve better development. It is inseparable from the promotion and promotion of online media. Internet media should be used to increase the propaganda of the cultural tourism industry and realize the organic integration of the cultural tourism industry and online media. It can accelerate the integration and development of tourism industry and cultural industry, and promote the development of online media. The online media should be able to timely understand the needs of consumers and the direction of market development, which can enhance the competitiveness of the cultural tourism industry and achieve better development.

\section{B. Improving Cultural Tourism Infrastructure}

On the one hand, infrastructure refers to tourism and transportation facilities. In the analysis of inferiority, it is mentioned that there are many areas in Shiyan City where there are many scenic spots, and the infrastructure construction directly restricts the integration and development of tourism industry and cultural products. Therefore, in the counties of Shiyan City, it is necessary to form a tourist road system. On the other hand, infrastructure also refers to the information infrastructure, which can establish a cultural tourism portal and improve the information support system so that tourists can learn first-hand information through the website.

\section{Establishing Special Funds to Expand the Source of Capital Investment}

Many industries are facing the shortage of funds in the integration of cultural industries and tourism industries, thus slowing down the integration process of the two industries. In order to promote the integration of the two industries, the government should further increase investment in the two industries and increase the financial support of related industries. It is mainly reflected in the following aspects: First, establish special funds. For the new development mode of the integration of cultural industry and tourism industry, a special development fund can be set up to make it convenient in fund source. Second, rationally expand the budget in this area. The government should appropriately increase the budget according to the progress of the integration of tourism industry and cultural industry, and reduce the shortage of funds in the development process. Third, expand the source of capital investment, establish special financing channels, vigorously guide and encourage social funds to participate in the development of cultural industries, relax market access conditions, and actively cultivate diversified investment entities. Due to the relatively small scale of tourism industry and cultural industry development in Shiyan City, there are some shortcomings in financing capacity. Therefore, the government can establish a special financing exchange platform for itself to weaken the shortage of funds.

\section{Strengthening Cooperation and Building a Tourism Industry Chain}

On the one hand, it refers to strengthening cooperation between the government and enterprises, cultivating the main body of the cultural market, and building a modern market system. The existing cultural enterprises in Shiyan City are small in number, small in scale and low in grade, and no industrial clusters are formed. The government should lower the threshold for the development of tourism culture enterprises, so that enterprises can expand their scale and improve their grades, so that tourism culture enterprises can form industrial clusters of a certain scale. Strengthening cooperation between government and enterprises is necessary and feasible. On the other hand, strengthen cooperation between enterprises, because the integration of tourism industry and cultural industry in Shiyan City is low, and the 
market share of cultural tourism is low, it is necessary to adopt a coalition of enterprises, and cooperation between enterprises is needed to expand market share and get more economic benefits. Strengthen cooperation among enterprises, form transportation integration, service integration, and information integration in the cooperation area, optimize the industrial chain, and form scale effect and coordination mechanism.

\section{E. Cultivating and Introducing High-end Compound Talents}

Talents have always been the promoters of social progress. Especially the development of new industries is very much driven by talents. In the new format of the integration of tourism industry and cultural industry, the demand for highend talents is particularly urgent, but there are few composite talents of both cultural knowledge and tourism knowledge. This requires the government to pay attention to the cultivation of compound talents. On the one hand, it is necessary to improve the talent management mechanism. According to the needs of tourism industry and cultural industry development, they must establish an excellent talent team, pay attention to talents, and constantly improve the talent incentive mechanism and strengthen the cultivation of talents to achieve the integration and development of the two major industries. On the other hand, it is necessary to establish a long-term mechanism for talent cultivation, and attach importance to the construction of talent classification system. It is necessary to encourage major universities and research institutions and other related organizations to carry out on-the-job training and continuing education of compound talents, and promote the interaction between research and industry and the combination of innovative talent development. In addition, it is also possible to introduce compound talents appropriately.

\section{F. Creating New Cultural Tourism Products and Innovating New Cultural Tourism Brands}

In the integration of cultural industry and tourism industry, a series of new cultural tourism products will be born. Enterprises should ensure the vitality of new cultural tourism products and participate in the process of integrating the two major industries to obtain a favorable position in the competition, with the integration of the two major industries, the new cultural tourism products will continue to optimize the spatial layout and form a cultural tourism area. It is necessary to actively seek new cultural tourism resources, so that resources that do not have cultural attributes are considered to be endowed with cultural connotations or to explore new types of resources, expand marketing channels, adapt to local conditions, and gradually integrate tourism culture industries in a timely manner.

Shiyan City can also innovate new types of cultural tourism brands based on the development of three famous brands such as "great mountain, clear river and Auto City". The tourism brand is a valuable intangible asset of the enterprise and is a manifestation of the company's strong competitiveness. The brand can reflect the uniqueness of the product and the thoughtfulness of the service.

\section{G. Strengthening System Construction and Improving Policy Support System}

For a long time, due to the nature of the tourism industry and the cultural industry, the two industries are serious across industries, and there are problems in the management of multiple departments. The communication and coordination are not smooth, resulting in overlapping administrative functions and inefficiency. The Shiyan municipal government should actively strengthen the system construction, coordinate the development of the cultural industry and the tourism industry, establish a good policy support system for the integration and development of the two major industries, break the original management system, and establish a special management department for the integration and development of the cultural industry and the tourism industry. Policies formulating should emphasize the importance of the cultural industry and the tourism industry, increase the intensity of the integration and development of the two major industries, guide the integration of the two major industries, enhance tourism through culture, and promote culture by tourism. For the tourism and cultural industries, the land for industrial enterprises is equivalent to the land for industrial projects, the relevant taxes and fees are reduced and exempted, and appropriate incentive policies are given to tourism culture enterprises that developed well. As the degree of integration of tourism industry and cultural industry is gradually increasing, it will change the development mode of the two major industries. The existing development policies are difficult to adapt to it. This requires the government to adapt to the requirements of economic development and being marketoriented, play their part and improve relevant development policies to provide good policy support for the integration and development of the two industries, ensure the free flow of tourism resources and cultural resources, and promote the integration of the two industries.

\section{H. High-tech Innovation Guides the Upgrading and Integration of Cultural Tourism Industry}

The advancement of technology is an important condition for the integration and development of tourism industry and cultural industry. The innovation of high technology accelerates the development of integration, and technological innovation often leads to new products. Enterprises should apply more high-tech, increase investment in cultural tourism industry, use technology to re-use cultural resources, enhance the economic added value of tourism products, and make science and technology play an important role in the integration of cultural industry and tourism industry.

\section{CONCLUSION}

The cultural industry and tourism industry in Shiyan City are showing an integration trend. The integration of the two industries is currently in its infancy. There are still many problems in the process of integration. Solving the problems encountered in the process of integration and upgrading the comprehensive strength of cultural tourism brand of Shiyan City, and promoting the integration of the two major industries are important tasks for the development of the two major 
industries and an important measure to achieve the great development of the two major industries.

\section{ACKNOWLEDGMENT}

Project: Hubei University of Automotive Industry College Student Innovation Fund Project (Project No.: DC2018074).

Wudang Culture Research and Communication Center Project of Hubei University Higher Education Humanities and Social Sciences Key Research Base Project: (Project No. 17wdjd016)

\section{REFERENCES}

[1] Xue Bingwang. Research on the Fusion Effect and Development Model of Cultural and Creative Industry and Tourism Industry[J].Journal of Southwest University for Nationalities(Humanities and Social Sciences),2015,36(01):168-171. (in Chinese)

[2] Cheng Xiaoli, Zhu Yawen. Research on the Integration Development of Tourism Industry and Cultural Industry in Anhui Province[J]. Economic Geography, 2012, 32(09): 161-165. (in Chinese)

[3] Huang Xijia, Zhou Qing. Strategies for the coordinated development of tourism and cultural industries based on industrial integration theory[J]. Corporate Economics, 2012, 31(09): 131-133 (in Chinese)

[4] Yan Youbing, Tan Lufei, Zhang Yinghui. Strategic Thinking on the Joint Development of Tourism Industry and Cultural Industry[J].Journal of Hunan Institute of Finance and Economics,2011,27(02):55-60. (in Chinese)

[5] Zhang Haiyan, Wang Zhongyun. Research on the Integration and Development of Tourism Industry and Cultural Industry[J].Resource Development \& Market,2010,26(04):322-326. (in Chinese) 